\title{
Review of Marti Kheel's Nature Ethics: An Ecofeminist Perspective
}

\author{
Rachel Fernflores \\ Philosophy Department \\ Women's and Gender Studies Department \\ California Polytechnic State University, San Luis Obispo, CA \\ rfernflo@calpoly.edu
}

\section{Book Review}

In Nature Ethics: An Ecofeminist Perspective, Marti Kheel accomplishes three main tasks. First, she convincingly argues that while holist nature ethicists Theordore Roosevelt, Aldo Leopold, Homles Rolston III, and Warwick Fox have each advanced our thinking about how we perceive and understand nature, they nevertheless each fail to grasp the tacit role that masculinity plays in their views. Second, she explains the strategies and insights that feminists, in particular ecofeminists, employ to understand our current relationships of dominance and exploitation over nature and the individuals therein, and she explains the value of some of the insights for rethinking those relationships. Third, she provides her own sketch of an ecofeminist holist philosophy, which she does not claim is complete. Instead, she seeks only to identify some of the basic beliefs and epistemological and moral stances of an ecofeminist holist. After briefly explaining some of the key issues she successfully raises in accomplishing each of these three tasks, I will suggest that as ecofeminist holists proceed to articulate the details of Kheel's ecofeminist holist philosophy, they would do well to develop an even broader holism than she suggests by gleaning insights from global feminist perspectives about women, class, and food production. My comments concerning the need for such a far reaching a holism speak primarily to the final, seventh chapter, entitled "Ecofeminist Holist Philosophy," because it is in that chapter that we begin to see the overall structure of Kheel's ecofeminist holist view. I will suggest that by taking the step to situate ecofeminist holism within the context of 
global feminism, the ecofeminist holist will be embracing the full scope and potential of her holism and its ambition.

In chapters one to six of her book, Kheel shows that the views of Roosevelt, Leopold, Rolston, and Fox are all limited by male bias insofar as each thinker conceives of nature as valuable only in the abstract. Thus, these thinkers display little or no interest in seeing individual other-than-humans animals as intrinsically valuable. By contrast, as Kheel argues, a key aspect of an ecofeminist holist account is that individuals in nature are not regarded as subordinate to the greater whole. In Roosevelt's, Leopold's, Rolston's, and Fox's views, individuals within nature, which Kheel calls "other-thanhuman animals," are not given comparable value to that of human animals or of nature as an abstracted whole. For instance, for Roosevelt and Leopold, an important way that human animals can find solace in nature is through the sport of hunting (Rolston's view does nothing to disavow the sport of hunting as a means of connecting with nature). While Warwick does not put stock in the value of hunting as a means of connecting with nature, he nevertheless conceives of nature as an expansion of one's human self. In all three views, the individual other-than-human animal is not morally significant and the fundamental moral stance toward nature is drawn from a deep appreciation of the concept of nature. In other words, what each thinker projects as a way of understanding nature, Kheel argues, does not fundamentally depart from traditional epistemological frameworks that hold that rational beings transcend their animal natures through reason by grasping abstract notions and using them for guidance.

Feminists have long argued that traditional epistemological frameworks requiring us to hold that reason is our greatest cognitive tool because it allows us to conceive of abstract wholes independent and indeed, in spite of, individual particulars, are limited by male bias (there are hundreds, if not thousands, of ways feminist have argued for these points. Here are just a few: Held 1998, Atherton 1993, Lloyd 1993, Jaggar 1991). For instance, as Virginia Held 
demonstrates, while the notion of the "man of reason" has evolved, it has nonetheless always been construed in opposition to the notion of the feminine. More specifically, it has always been construed as excluding what has been understood as feminine. There are many ways feminists have made these observations. One way that the identification of reason with maleness has been justified is through an analysis of the traditional understanding of the distinction between the roles men occupy in the public sphere and the ones women occupy in the private sphere. The traditional assumption is that in the public realm, men transcend their animal nature by creating government, law, philosophy, art, and they do these things by discovering abstract principles (moral, mathematical, etcetera), and using those abstractions as guides. By contrast, in the private realm, what women do is reproduce. Reproduction is (still) usually conceived of as being only a biological act that is not a conscious, determinate act of creativity. Instead, it is what women do by nature as physical beings. Consequently, women have not been thought of as transcending their animal nature and thus, what guides them is not moral principles or other abstractions, but their physicality. This is thought to be so in spite of the obvious ways in which reproduction and child rearing are governed by social and cultural practices we create. The man of reason, then, adopts an epistemological stance that siphons off the emotions, the physicality of being, and feelings of unity with individuals in one's surroundings and instead, attends only to abstract principles and constructions to find guidance (Held 1998, 93-94 and 102-104).

Kheel situates each of Roosevelt's, Leopold's, Rolston's, and Fox's view within such a traditional epistemological framework. Broadly speaking, these nature ethicists think that we transcend our animal natures by seeing ourselves as different from nature. In so seeing, we find ourselves alienated from nature, yet desiring meaningful connections with nature. We act on the desire for connection through domination, control, and violence. By analogy, feminists have argued that we can understand male dominance over women, expressed through violence, by the simultaneous 
unconscious alienation from women and accompanying desire for deep connections with other fellow human beings. The epistemological move is the same in each case: distance, abstract, control, dominate.

As Kheel shows, the ecofeminist is a nature ethicist of a different ilk than nature ethicists who develop their views within the constraints of traditional male-centered epistemological frameworks. Ecofeminists explore intersections between dominance and exploitation of nature and dominance and exploitation of oppressed people, particularly women. While Kheel does not claim to speak for all ecofeminists, she does identify several components that any ecofeminist view will contain. I will refrain from a detailed account of all of the component beliefs and practices Kheel sets out in her analysis and instead, only mention the most significant components.

An ecofeminist philosophy, according to Kheel, will have a central place for the moral significance of empathy, care, and the priority of individuals over the abstract. As she demonstrates, many ecofeminists find aspects of Carol Gilligan's "ethic of care" approach to moral decision making useful for exploring alternative epistemological and moral stances we can take toward nature and individuals therein. In taking an ethic of care approach to moral decision making, one considers ways of preserving relations and maintaining connections between those affected by various moral resolutions, as opposed to the more traditional "ethic of justice" approach, which involves ascertaining which moral abstract principles are relevant to any given moral situation and then applying them on the basis of purported rational and objective criteria. In addition, Kheel points out that Simone Weil's conception of "attentive love," particularly in its more secular form as conceived by Iris Murdoch, is similarly promising for many ecofeminists. Attentive love involves developing our ability to attend to the other in a way that involves seeing the other through empathetic eyes. Kheel accurately explains the wide range of ways that feminists have been (rightly or wrongly) critical of the "ethic of care" approach, as well as 
Gilligan's own methodology and views, but contends that in spite of these criticisms, the ethic of care approach to figuring out what is morally relevant holds much promise, just as the notion of attentive love can be useful for stressing the importance of being conscious about where we direct our attention and how our agency is shaped by those directions. What is important, Kheel argues, is that the conception of care one uses is a conception of what she calls "contextualized care." Contextualized care allows for respectful and empathetic attention to the quality of life of every individual with the conscious intent not to exploit or otherwise harm or sacrifice any individual.

Kheel does much more in her book than I have outlined and what she does, she does well. Among the attitudes and practices Kheel argues fall out of an ecofeminist holist account is a commitment to veganism (or at the very least, vegetarianism). Rather than develop a rational argument that might encourage others to adopt a vegan diet, she chooses instead to "reverse the onus of justification, asking those who consume animals and their products to explain the rational foundation of their dietary choice" (Kheel 2008, 235). In other words, she is less interested in making a rational argument that we should care and more interested in asking why we do not care. Her approach is laudable, not just because the vegan obviously makes a dietary choice that allows for less suffering than the human carnivore. It is also strategically laudable, because attempting to construct a rational argument that we should care and respect individuals, not just the abstract whole of nature, would be something of a distraction and possibly even a departure from her view concerning the value of contextualized care in ecofeminist holism. The notion of contextualized care does not obviously admit of a rational justification, if what one would hope for from such an account is that we would feel compelled to care as a result of seeing the rational abstractions developed. As Kant points out, "love as an inclination cannot be commanded" (Kant 1993, 12). It is doubtful that we can command or "show," from reason and rational argumentation, that we should be empathetic toward others or even 
caringly attentive because of their intrinsic value or their potential for suffering. Empathic and emotional attention toward others can come about when we choose to attend to seeing the intrinsic value of individual others, but it is not obvious we can argue ourselves or others into being empathetic and emotively attentive toward others on the basis of rational abstractions. We can develop "recognition" respect for others on the basis of rational abstractions that say that at least a human animal is worthy of respect in virtue of his or her humanity upon recognition of that humanity, but this is a different form of respect from appraising them as excellent in some way (Dillon 1995, 292-293), and it is not to say that they are worthy of attitudes of empathy and care.

In her account, Kheel faces a classic feminist challenge, namely that it is extremely difficult to land on a reason-based argument for the importance of feeling empathy and care toward other individuals, especially in the face of a historical and traditional stance toward them that denies their worth as individuals. In the particular case of veganism, we can point to objective facts about ways in which the diet may improve overall health and extend individual lives, but those salient points speak to our desire to be happy and most of us assume, by reflex, that our chances of being happy are tied to being healthy and alive. Pointing to an individual's health and long life as a result of a plant based diet is not the same as making a rational case for the importance of empathy and care toward all living creatures. In reversing the burden of justification, Kheel not only avoids the difficulty of making a reason-based case for the value of empathy and care, she chooses to highlight some of the abhorrent ways that otherthan-human animals are treated for the purpose of human consumption. In so doing, she makes it extremely difficult, if not impossible, for someone who desires to think of herself as having a compassionate, empathetic, and caring perspective, to justify eating animals and consuming their products once she knows the extent of the exploitation to which they are subjected. 
I agree with Kheel that it is incumbent upon the ecofeminist holist, who views nature as a whole as valuable, but more importantly, all individuals, human and other-than-human animals, as morally significant, to adopt a life of veganism. It is unclear from her discussion of ecofeminism, veganism, and vegetarianism, whether Kheel's view is that the only consistent ecofeminist holist is a vegan. However, only veganism, as Kheel sets it out, can preclude the immoral treatment of other-than-human animals altogether, since vegetarianism likely does not do so for obvious reasons concerning the production of, say, dairy products. Veganism is the only fully consistent and credible position the ecofeminist holist can hold. Indeed, it feels in the text that Kheel thinks that veganism is the clear choice, even if she often talks about "vegetarianism or veganism" in her notion of "contextualized care," which again, is the careful, conscientious and conscious care she argues we need to cultivate in order to have a relationship with nature and individuals therein that is consistent with ecofeminist holism. Nevertheless, Kheel is clearly correct to argue that both the vegan and the vegetarian are living lives that are likely to be healthier and more caring of all individuals, and that these are choices that fall naturally out of identifying oneself as an ecofeminist.

Kheel addresses many criticisms of animal advocacy and veganism in her final chapter that come from a wide variety of sources. It is in her responses to two of those criticisms that I believe Kheel fails to explore how much more holist her account could be. The first concerns the criticism of animal advocates that they spend time and energy on other-than-human animals, not human beings. Kheel points out that caring can extend to a wide range of beings, including plants and human beings (Kheel 2008, 239). I agree with Kheel on this point. However, I would encourage her to fill in her sketch of an ecofeminist holist philosophy with careful attention to the importance of rejecting participation in the exploitation of all individuals. The vegan makes meaningful and conscious dietary choices, but she needs to be careful about the risk of false consciousness and possibly self-righteousness. In developed and 
under-developed parts of the world there is a great deal of exploitation of human animals in the production of fruit, vegetables, and grains. There is also significant damage done to the environment for the purpose of such food production. It is incumbent upon an ecofeminist holist to develop a holism that refuses to participate in a system that sees any living creatures as insignificant. This means that beyond setting out the treatment of other-than-human animals to turn them into food, the ecofeminist holist needs to encourage the development of a robust and deep understanding of how food production works in the local and global context with a mind to underscoring how many individuals, other-than-human and human, are sacrificed, for the benefit of mostly the middle and upper class of Western industrialized nations. For instance, Ellen O'Loughlin's ecofeminist analysis of the United Farm Workers grape boycott in the late1980's-mid 1990's still stands as a shining example of ways we can think ecologically about food and women, and why we should think about these connections (O'Loughlin 1994, 680-688).

One way the ecofeminist holist can become more holist in her approach is by including support for insights from global feminists, many of whom have argued that the feminization of poverty is unacceptable. Men, women, and children work in deplorable conditions for the sake of food production, either directly or indirectly, across the globe. However, as feminists have argued, it is women and often, children, in the global context who bear the brunt of poor working conditions and poverty. As Victoria Davion discusses, approximately seventy percent of the world's human population work in the production of food and most of those are impoverished women who work to produce unsafe food in unsafe conditions (Davion 2008, 81-94). Susan Shaw and Janet Lee explain that globally, women constitute fifty-one percent of the agricultural labor force, yet only fifteen percent of the world's agricultural extension agents are women (Shaw and Lee 2008, 431). On average, in the global context, women work longer hours than men in the cultivation of agricultural products, but few female farmers own land or the means of production (Shaw and Lee 2008, 431-432). 
Ecofeminist holists who find promise in the ethic of care approach, as Kheel does, can refine the ethic of care approach by applying it in the global context, as Virginia Held does (Held 2008, 43-57; Held 2006). In addition, the ecofeminist holist can respond to charges of neglect of human individual sacrifices for the sake of food production by extending her support to global feminists who advocate for rethinking principle-based respect for the sovereignty of nation states in the interest of breaking down cultural barriers to equality and dignity for all (e.g., Dietz 1998, 378-400). Such a vision, while at first overwhelming, could nevertheless go a great distance toward a holism that is fully diverse and inclusive. The ecofeminist holist need not turn all of her attention to these other causes, but instead, she can seek insight from others whose attention is directed toward such causes and possibly even find allies in others who seek to take an ecofeminist holist approach to life. There is room in Kheel's view for global feminism, and an ecofeminist holist philosophy cannot afford to underestimate just how ambitious and expansive her holism needs to be.

Expanding the scope of the ecofeminist holist philosophy to include a greater acknowledgement of the exploitation of other-thanhuman and human animals by drawing insight from global feminism will address a second criticism of vegetarianism Kheel mentions. Vegans are sometimes accused of being insensitive toward the dietary traditions of other cultures. They are also susceptible to the accusation of elitism. In response, Kheel argues that vegetarianism is a tradition of many cultures, such as some Hindu and Buddhist cultures, and consequently, it is as legitimate as any other cultural dietary tradition (Kheel, 2008: 236). Kheel is correct that the vegan in fact harms fewer creatures due to her dietary choices, and for this the vegan is to be applauded. However, if the vegan makes these choices in the interest of ecofeminist holism, she needs to take the issues of tradition and elitism head on, so that she can explain in much greater detail the commitments and consequences of ecofeminist holism. Veganism, in the developed world, is simply not on a par with traditional vegetarian Hindu and Buddhist cultures, 
even if the motivation behind the dietary choice, namely to embody "the ideal of nonviolence" is often the same. Usually, to be a healthy vegan in the developed world, one must not only participate in a local and global system that allows for, indeed depends on, the exploitation of human animals in the productions of food, one also needs to have certain advantages. A healthy vegan in the developed world is in possession of a considerable amount of knowledge. It takes time and money to accrue the kind of culinary and health awareness the healthy vegan enjoys. A vegan who eats only organic food, thereby decreasing her participation in a system that damages the environment and reducing her carbon footprint, is also to be applauded. Yet, again, it is important to observe that only someone with considerable resources can make such a choice. It is not just that organic food is expensive, but also, a balanced diet of vegan food takes more time and knowledge to prepare when compared to the many processed, inexpensive non-vegan and non-vegetarian foods readily available. As we move to the global context, the situation is even more dire, since most people who live in poverty are going to eat not just what is traditional, but whatever is around, with little or no knowledge of how it has been produced or whether it is healthy for them. The ecofeminist holist is uniquely positioned to take the lead against the objections concerning tradition and elitism by arguing that we should set up our societies so that everyone is in a position to make the dietary choice that the ecofeminist holist vegan makes. In so arguing, she must argue for the value of widespread dietary and culinary education, as well as for greater opportunity of social mobility for underprivileged groups.

Kheel wrote an excellent book, but it is in need of a sequel, one that spells out in far greater detail the scope of an ecofeminist holism. She has identified male bias in prominent approaches to nature ethics and has clearly articulated why taking a care approach to nature ethics, along with an ecofeminist approach, means that the ecofeminist holist needs to embrace a life that involves causing as little harm and disruption as possible to the well being and flourishing of individual human and other-than-human animals. 
However, I believe the ecofeminist holist needs to think as big as the word "holist" allows, and this means that she needs to see how ambitious holism really is. Kheel makes a convincing case against the nature ethicists she discusses and also for her view that the burden of providing a rationale for dietary choices should be hoisted on the shoulders of those who eat meat, not on the vegan (and possibly also the vegetarian). However, I think her ecofeminist holism can now go on the offensive and become even more holistic by addressing the criticisms of veganism and vegetarianism much more directly. Such an offensive approach can begin by acknowledging the role that privilege and opportunity play in the choice of the typical vegan and vegetarian in the developed parts of the world, and then advocating for some of the reforms global feminists advance.

\section{References}

Atherton, Margaret. 1993. Cartesian reason and gendered reason. In A mind of one's own: Feminist essays on reason and objectivity, eds. Louise Antony and Charlotte Witt, 19-34. Boulder, Colorado: Westview Press.

Davion, Victoria. 2008. Food fights: A feminist perspective. In Global feminist ethics: Feminist ethics and social theory, eds. Rebecca Whisnant and Peggy DesAutels, 81-94. Lanham, Maryland: Rowman \& Littlefield Publishers, Inc.

Dietz, Mary. 1998. Context is all: Feminism and theories of citizenship. In Feminism \& politics, ed. Anne Philips, 378-400. New York: Oxford University Press.

Dillon, Robin S. 1995. Toward a feminist conception of self-respect. In Dignity, character, and self-respect, ed. Robin S. Dillon, 290-310. New York, New York: Routledge.

Held, Virginia. 2008. Gender identity and the ethics of care in globalized society. In Global feminist ethics: Feminist ethics and social theory, eds. Rebecca Whisnant and Peggy DesAutels, 43-57. Lanham, Maryland: Rowman \& Littlefield Publishers, Inc.

Held, Virginia. 2006. The ethics of care: Personal, political, and global. New York, New York: Oxford University Press. 
Jaggar, Allison. 1991. Feminist ethics: Problems, project, prospects. In Feminist ethics, ed. Claudia Card, 78-104. Kansas: University of Kansas Press.

Kant, Immanuel. 1993. Grounding for the metaphysics of morals, trans. James W. Ellington. 3rd Edition. Indianapolis: Hackett Publishing Company, Inc.

Kheel, Marti. 2008. Nature ethics: An ecofeminist perspective. Lanham, Maryland: Rowman \& Littlefield Publishers, Inc.

Lloyd, Genevieve. 1993. Maleness, metaphor, and the "crisis" of reason. In A mind of one's own: Feminist essays on reason and objectivity, eds. Louise Antony and Charlotte Witt, 19-34. Boulder, Colorado: Westview Press.

O’Loughlin, Ellen. 1994. Questioning sour grapes: Ecofeminism and the United Farm Workers grape boycott. In Living with contradictions: Controversies in feminist social ethics, ed. Alison M. Jaggar, 680-688. Boulder, Colorado: Westview Press.

Shaw, Susan M. and Janet Lee. eds. 2007. Women and agriculture. In Women's voices feminist visions: Classic and contemporary readings. 3rd Edition. New York, New York: McGraw Hill. 